\title{
Soy Isoflavone Aglycone Modulates A Hematopoietic Response in Combination with Soluble $\beta$-Glucan: SCG
}

\author{
Toshie Harada, ${ }^{a}$ Susumu MAsuda, ${ }^{b}$ Masayuki ArII, ${ }^{b}$ Yoshiyuki Adachi, ${ }^{a}$ Mitsuhiro NaKaJima, ${ }^{c}$ \\ Toshiro YADOMAE, ${ }^{a}$ and Naohito OHNO ${ }^{*, a}$ \\ ${ }^{a}$ Laboratory for Immunopharmacology of Microbial Products, School of Pharmacy, Tokyo University of Pharmacy \& Life \\ Science; 1432-1 Horinouchi, Hachioji, Tokyo 192-0392, Japan: ${ }^{b}$ Kikkoman Co.; Chiba 278-8601, Japan: and \\ ${ }^{c}$ Minahealth Co., Ltd.; Saitama 360-0212, Japan.
}

Received June 28, 2005; accepted September 13, 2005; published online September 20, 2005

Soy isoflavone aglycones (IFAs) have a wide range of biological actions that suggest they may be of use in cancer prevention. On the other hand, a branched $\beta$-glucan from Sparassis crispa (SCG) is a major 6-branched 1,3- $\beta$-D-glucan in an edible/medicinal mushroom: Sparassis crispa showing antitumor activity. We have previously reported that both oral and intraperitoneal administration of SCG enhanced the hematopoietic response in cyclophosphamide (CY)-induced leukopenic mice. In this study, we investigated the hematopoietic response due to IFA in combination with SCG in CY-induced leukopenic mice. The oral administration of IFA in combination with SCG synergistically enhanced the number of white blood cells, and increased spleen weight. Analyzing the leukocyte population by flow cytometry, the combination of IFA and SCG increased the number of monocytes and granulocytes in the spleen. Taken together, the combination of IFA and SCG synergistically provides the hematopoietic responses that are enhanced over IFA or SCG alone.

Key words soy isoflavone aglycone; $\beta$-glucan; branched $\beta$-glucan from Sparassis crispa (SCG); hematopoietic response

Epidemiological evidence and experimental data from animal studies strongly support the beneficial effects of isoflavones on human health. ${ }^{1)}$ Isoflavone aglycones (IFAs) are highly bioactive due to their unimpeded intestinal absorption, unlike their related glycosides, which are not absorbed across enterocytes. Glycosylated isoflavones are converted to aglycones via hydorolysis catalyzed by $\beta$-glycosidase, an intestinal enzyme that is also commonly found in microorganisms, plants and some basidiomycete mushrooms. In mammalian systems, soy isoflavones exhibit a number of biological activities, including inhibition of cell proliferation, ${ }^{2,3)}$ antioxidative effects, ${ }^{4)}$ and enzyme-inhibitory effects. ${ }^{5)}$ In addition, dietary soy isoflavonoids have been considered for the treatment and prevention of hormone-dependent diseases. ${ }^{6}$

An immunomodulating substance, biological response modifier (BRM), or biotherapy, including immunotherapy fields, is important for the treatment of cancer. Some $\beta$-glucans are well-known BRMs; the mushrooms from which they are derived are widely distributed in nature and are used as medicine and food. ${ }^{7)}$ Among the $\beta$-glucans, 6-branched 1,3$\beta$-glucan is the most well-characterized. We have analyzed the mechanism of $\beta$-glucan-mediated immunopharmacological activity and identified the conformation-dependent and -independent activity. ${ }^{8,9)}$ Sparassis crispa is a medicinal mushroom that recently became cultivatible in Japan. The primary structure of the major the cold $\mathrm{NaOH}$ extracted polysaccharide fraction from $S$. crispa was found to be 6branched 1,3- $\beta$-glucan, having one branch approximately every third main chain. The fraction showed strong antitumor activity against the solid form of Sarcoma 180 in ICR mice. ${ }^{10)}$ In our recently study, we applied $S$. crispa to several cancer patients in combination with lymphocyte transplantation immunotherapy and obtained a good response. ${ }^{11)}$ To examine the pharmacological applicability of $S$. crispa $\beta$-glucan, a branched $\beta$-glucan from Sparassis crispa (SCG) was purified from the cold $\mathrm{NaOH}$ extracted fraction, and showed immunopharmacological activities. ${ }^{11-17)}$
Numerous attempts have been made by scholars to demonstrate the pharmaceutical effect of soy products. However, there have been few studies on their immunomodulatory effect. Dietary soy phytoestrogens may influence the differentiation, signaling and actions of numerous cells of the immune system, as the receptors have been identified on many cell types, including lymphocytes and antigen presenting cells. In fact, there is growing interest in the host immune function, including aspects related to tumor initiation and growth, in addition to other potential health benefits. We have designed this experiment, which is based on the premise that isoflavone may work as a immunomodulating agent. In a previous study, we reported that both oral and intraperitoneal (i.p.) administration of SCG enhanced the hematopoietic response in CY-induced leukopenic mice from a qualitative as well as quantitative point of view. ${ }^{12,13)}$ In this study, we show that the combination of IFA and SCG provides hematopoietic responses that are synergistically enhanced over isoflavone or $\beta$-glucan alone.

\section{MATERIALS AND METHODS}

Preparation of SCG Fruit bodies of Sparassis crispa were cultured by Minahealth Co., Ltd. (Saitama, Japan). SCG was prepared as previously described. ${ }^{12)}$ Briefly, airdried and powdered $S$. crispa was extracted with cold alkali $\left(10 \% \mathrm{NaOH} / 5 \%\right.$ urea, $\left.4{ }^{\circ} \mathrm{C}, 2 \mathrm{~d}\right)$. The extract dissolved in $8 \mathrm{M}$ urea was applied to a DEAE Sephadex A25 $\left(\mathrm{Cl}^{-}\right)$column equilibrated with $8 \mathrm{M}$ urea, the passed-through fraction was collected and extensively dialyzed against tap and distilled water, and then lyophilized (elemental analysis $\mathrm{C}: \mathrm{H}: \mathrm{N}=$ $40.06: 6.77: 0.08$ ). SCG solution was prepared by dissolution in $0.5 \mathrm{~N} \mathrm{NaOH}$, followed by immediate dialysis against saline for $3 \mathrm{~d}$. After dialysis, the non-dialyzable fractions were autoclaved and frozen until use.

Preparation of Isoflavone Aglycone (IFA) FSBE (Fermented Soybean Extract) was provided by Kikkoman Co. 
Ltd. (Chiba, Japan) as a yellow-brown powder. FSBE rich in the two major isoflavone aglacone, genistein and daidzein, was used as the source of IFA. FSBE was obtained by ethanol/water extraction and purification from fermented soybean. ${ }^{18)}$ The composition of FSBE was $341 \mathrm{mg} / \mathrm{g}$ isoflavones as the aglycone form $(193 \mathrm{mg} / \mathrm{g}$ genistein, $148 \mathrm{mg} / \mathrm{g}$ daidzein and trace of glycitein), $183 \mathrm{mg} / \mathrm{g}$ protein, $258 \mathrm{mg} / \mathrm{g}$ carbohydrate, $116 \mathrm{mg} / \mathrm{g}$ fat, $16 \mathrm{mg} / \mathrm{g}$ moisture, $24 \mathrm{mg} / \mathrm{g}$ ash and $62 \mathrm{mg} / \mathrm{g}$ fiber. For analysis of isoflavones in the extract, $1 \mathrm{mg}$ of the extract was mixed with $2.5 \mathrm{ml}$ of dimethyl sulfoxide, and the solution was sonicated with an ultrasonicator (Branson, Model B1210J-DTH, Tokyo, Japan). Concentrations of isoflavones (genistein, daidzein) in a solution were analyzed by HPLC with a CAPCELLPAK C18 AG120 column (4.6 mm $\times 150 \mathrm{~mm}$, Shiseido, Tokyo, Japan) A mixture of acetonitrile/water/trifluoroacetic acid $(25: 75: 0.1, \mathrm{v} / \mathrm{v} / \mathrm{v})$ was used as the mobile phase at a flow rate of $1.0 \mathrm{ml} / \mathrm{min}$. Isoflavones in the eluate were detected by their absorbance at $254 \mathrm{~nm}$. The concentration was calculated from the standard curve of the authentic compound.

Materials Turk's solution was purchased from Wako Pure Chemical Co. Cyclophosphamide (CY) was from Shionogi \& Co., Ltd., Osaka.

Animals ICR male mice between 6 and 7 weeks of age were purchased from Japan SLC, Shizuoka. The experimental protocol was approved by the Committee of Animal Care and Use of Tokyo University of Pharmacy and Life Science. Mice were maintained under specific pathogen free (SPF) conditions, at $23 \pm 1{ }^{\circ} \mathrm{C}$, with a constant humidity of $55 \pm 5 \%$, under a cycle of $12 \mathrm{~h}$ of light and $12 \mathrm{~h}$ of dark and had free access to food and tap water according to the Guideline of Experimental Animal Care issued by the Prime Minister's Office of Japan.

Counting of White Blood Cells (WBCs) Mice were treated with CY $(200 \mathrm{mg} / \mathrm{kg})$, and SCG $(200 \mu \mathrm{g} / \mathrm{mouse})$ was immediately administered i.p. to the CY-treated mice, while IFA $(15 \mathrm{mg} /$ mouse $)$ was orally administered for 2 weeks. WBCs were removed from the tail vein of these mice. WBC numbers were counted by mixing blood $(5 \mu \mathrm{l})$ with Turk's solution $(95 \mu \mathrm{l})$.

Preparation of Splenocytes for FACS Mice were treated with CY (200 mg/kg), and SCG (200 $\mu \mathrm{g} / \mathrm{mouse})$ was immediately administered i.p. to the CY-treated mice, while IFA ( $15 \mathrm{mg} /$ mouse) was orally administered for 2 weeks. Thirteen days after administration, the spleen was teased apart in $1 \times$ PBS, and after centrifugation the single cell suspension was treated with ACK-lysing buffer $\left(8.29 \mathrm{~g} / 1 \mathrm{NH}_{4} \mathrm{Cl}\right.$, $1 \mathrm{~g} / 1 \mathrm{KHCO}_{2}, 37.2 \mathrm{mg} / \mathrm{l} \mathrm{EDTA} / 2 \mathrm{Na}$ ) to lyse the red blood cells. After centrifugation, splenocytes were maintained in $1 \times$ PBS supplemented with $0.1 \% \mathrm{NaN}_{3}$ and $2 \%$ heat-inactivated fetal calf serum (FCS).

Flow Cytometry Splenocytes were stained with FITCand PE-conjugated mAbs. To block the FcR-mediated binding of the $\mathrm{mAb}$, anti-mouse CD16/CD32 FcBlockTM (Pharmingen Co., U.S.A.) was added. The cells were analyzed on a FACSCalibur, and the data were processed using the CELLQuest program. The following mAbs were used for immunofluorescent staining: FITC-anti mouse CD11b (Mac1), FITC-anti mouse Ly-6G (Gr-1), PE-anti mouse CD3- $\varepsilon$, FITC-anti mouse B220, PE-anti mouse CD4, FITC-anti mouse $\mathrm{CD} 8 \alpha$ (Pharmingen Co., U.S.A.).
Statistical Analysis The results were expressed as the means \pm standard deviation (S.D.). The significance of differences between the means was measured by Student's $t$-tests.

\section{RESULTS AND DISCUSSION}

The objective of this study was to identify possible synergistic effects between $\beta$-glucan and IFA on the hematopoietic response in CY-induced leukopenia. CY $(200 \mathrm{mg} / \mathrm{kg})$ was administered i.p. to ICR mice on day 0 . Immediately after CY administration, SCG ( $200 \mu \mathrm{g} / \mathrm{mouse})$ was administered i.p. to the CY-treated mice, and IFA was orally administered for 2 weeks. The number of WBCs was monitored for 2 weeks. Figure 1 shows the kinetics of the WBC count. The number of WBCs was significantly reduced within $3 \mathrm{~d}$ after the $\mathrm{CY}$ treatment. The peak of the WBC count appeared on day 9 in the saline-treated groups. There were no significant changes of the number of WBCs between saline- and saline+IFAtreated groups. The SCG- and SCG+IFA-treated groups enhanced the recovery of the WBC count compared with the saline-treated group. The WBC counts in SCG+IFA-treated group were significantly higher than that in SCG-treated group on day 9, 11 and 13. These results suggested that the oral administration of IFA in combination with SCG synergistically enhanced the hematopoietic response.

Next, we examined the effect of the combination of IFA and SCG on spleen weight in CY-treated mice on day 13. Compared with the saline control, treatment with IFA alone did not alter the spleen weight, and treatment with SCG alone significantly increased the spleen weight (Fig. 2). The combination of IFA and SCG acted synergistically to increase the spleen weight.

In a previous study, we reported that the leukocyte recovery in CY-treated mice was different in each population, such as granulocytes, macrophages, natural killer cells, B cells and $\mathrm{T}$ cells. Both oral and intraperitoneal administration of SCG modulated the recovery rate of each population, and recovered such populations in the peritoneal cavity, liver, spleen and bone marrow (BM) faster than in the control group. ${ }^{12,13)}$ On the other hand, recent studies have suggested

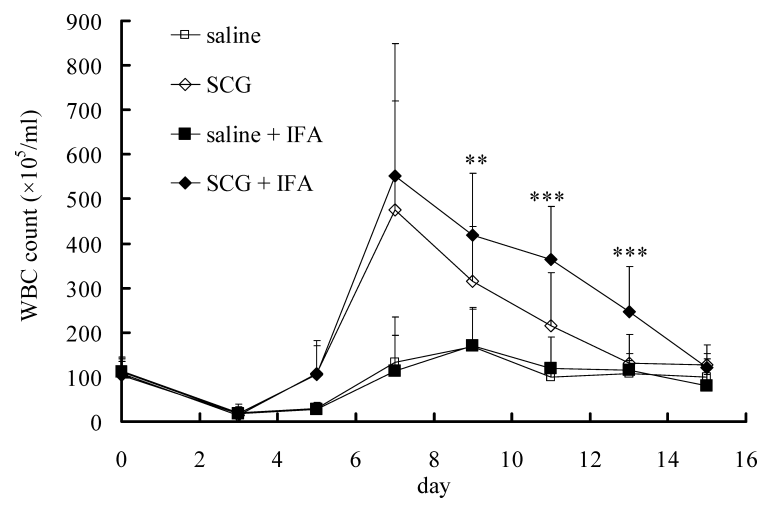

Fig. 1. Kinetics of the White Blood Cell (WBCs) Number in CY-Induced Leukopenic Mice Administered with SCG and/or IFA

$\mathrm{CY}(200 \mathrm{mg} / \mathrm{kg})$ was i.p. administered to ICR mice on day 0 . Immediately after CY administration, SCG $(200 \mu \mathrm{g} /$ mouse $)$ was i.p. administered to these mice and IFA $(15 \mathrm{mg} /$ mouse) was orally administered for 2 weeks. The WBC number was counted on day $0,3,5,7,9,11,13$ and 15 by mixing blood ( $5 \mu 1$, tail vein) with Turk's solution $(95 \mu 1)$. The data shows one of three experiments performed with similar results, each evaluating three mice per group. Values represent mean \pm S.D. Significant difference from the SCG-treated group, $* * p<0.01, * * * p<0.001$. 
that soy isoflavones have a suppressive effect on some macrophage functions, such as platelet aggregation, inflammation, cell adhesion and chemotaxis. ${ }^{3)}$ To examine the effect of combination therapy on macrophage proliferation, the cell surface antigens of splenocytes were tested with flow cytometry. On day 13, splenocytes were stained with PE-antimouse CD11b (Mac-1) and FITC-anti-mouse Ly-6G (Gr-1). Compared with the saline, the IFA treatment did not inhibit the macrophage proliferation $\left(\mathrm{Mac}-1^{+} \mathrm{Gr}-1^{-}\right.$cell) (Fig. 3). The combination treatment of SCG and IFA, as well as that of SCG alone, increased the number of macrophages and granulocytes $\left(\mathrm{Mac}-1^{+} \mathrm{Gr}-1^{+}\right.$cell), more than saline treatment. These results suggested that IFA promoted the hematopoietic response, and did not inhibit the proliferation of macrophages in the CY-treated mice.

Next, to examine the effect of the combination therapy on the proliferation of other leukocytes, the cell surface antigens of splenocytes were tested with flow cytometry. On day 13, splenocytes were stained with PE-anti mouse CD $3 \varepsilon$ and FITC-anti mouse B220, or PE-anti mouse CD4 and FITC anti-mouse $\operatorname{CD} 8 \alpha$. The IFA treatment did not alter the population of $T$ cells and B cells in the spleen (Fig. 4). These results suggested that IFA may augment the number of leukocytes enhanced by SCG, without changing the cell population modulated by SCG.

Taken together, the combination of soy isoflavone: IFA and soluble $\beta$-glucan: SCG provides a hematopoietic response that is synergistically enhanced over IFA or SCG alone. Reconstruction of the hematopoietic response is an important

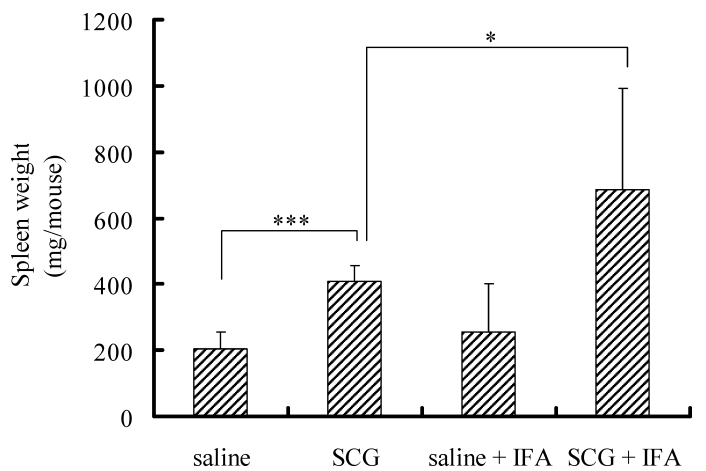

Fig. 2. Effect of SCG and IFA Administration on Spleen Weight in CY-Induced Leukopenic Mice

CY $(200 \mathrm{mg} / \mathrm{kg})$ was i.p. administered to ICR mice on day 0 . Immediately after CY administration, SCG $(200 \mu \mathrm{g} /$ mouse $)$ was i.p. administered to these mice and IFA $(15 \mathrm{mg} /$ mouse) was orally administered for 2 weeks. Spleen weight was measured on day 13. The data shows six mice per group. Values represent mean \pm S.D. Significant difference from control group, $* p<0.05$, $* * * p<0.001$.

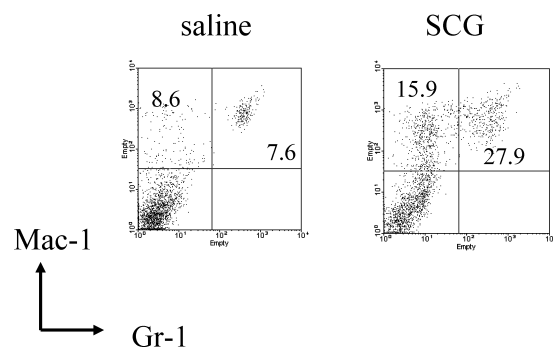

event in chemotherapy for advanced cancer patients. Recently, techniques to use the hematopoietic progenitors in the peripheral blood or in cord blood have been significantly improved by developing applications of cytokines, their genes or their inducers. The data shown here may provide proof of the efficacy of the combination therapy of isoflavones and $\beta$ glucan as a candidate for these medical treatments.

In this study, we used FSBE (Fermented Soybean Extract), which rich in the two major isoflavone aglacone, genistein and daidzein, as the source of IFA. The composition of FSBE was $341 \mathrm{mg} / \mathrm{g}$ isoflavones as the aglycone form $(193 \mathrm{mg} / \mathrm{g}$ genistein, $148 \mathrm{mg} / \mathrm{g}$ daidzein and trace of glycitein), $183 \mathrm{mg} / \mathrm{g}$ protein, $258 \mathrm{mg} / \mathrm{g}$ carbohydrate, $116 \mathrm{mg} / \mathrm{g}$ fat, $16 \mathrm{mg} / \mathrm{g}$ moisture, $24 \mathrm{mg} / \mathrm{g}$ ash and $62 \mathrm{mg} / \mathrm{g}$ fiber. As mentioned above, the present experimental results were shown the actions of crude isoflavone. Although the mechanism by which the combination of IFA and SCG enhances the hematopoietic response and the active substance(s) have not been precisely established, our observation is of considerable

(a)

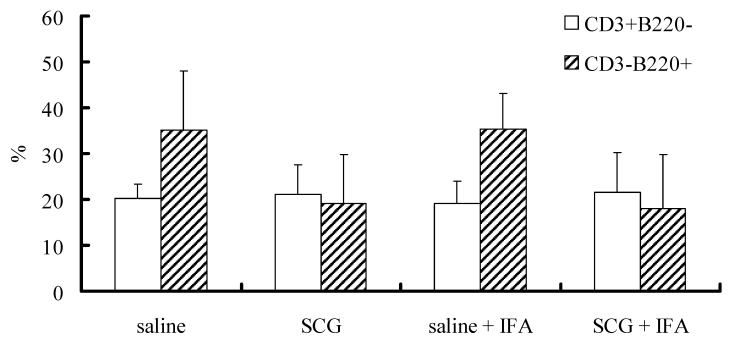

(b)

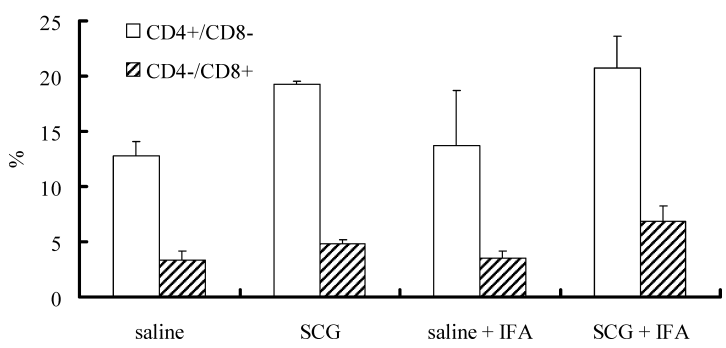

Fig. 4. Effect of SCG and IFA Administration on T Cells and B Cells in CY-Induced Leukopenic Mice

CY $(200 \mathrm{mg} / \mathrm{kg})$ was i.p. administered to ICR mice on day 0 . Immediately after CY administration, SCG $(200 \mu \mathrm{g} /$ mouse $)$ was i.p. administered to these mice and IFA $(15 \mathrm{mg} /$ mouse) was orally administered for $13 \mathrm{~d}$. Splenocytes were isolated from these mice on day 13. These cells were stained for antibodies: i.e., PE-anti mouse CD3- $\varepsilon$ and FITC-anti mouse B220, PE-anti mouse CD4 and FITC-anti mouse CD8 $\alpha$ then analyzed with flow cytometry, as described in the Experimental procedures. The data shows one of at least four experiments performed with similar results, each evaluating two mice per group.
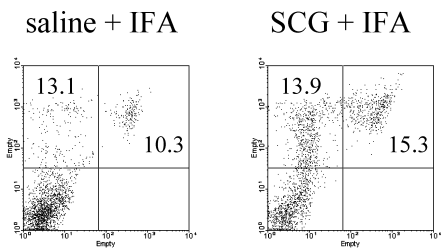

Fig. 3. Effect of SCG and IFA Administration on Macrophages and Granulocytes in CY-Induced Leukopenic Mice

CY $(200 \mathrm{mg} / \mathrm{kg})$ was i.p. administered to ICR mice on day 0 . Immediately after CY administration, SCG (200 $\mu \mathrm{g} / \mathrm{mouse})$ was i.p. administered to these mice and IFA $(15 \mathrm{mg} /$ mouse) was orally administered for $13 \mathrm{~d}$. Splenocytes were isolated from these mice on day 13 . These cells were stained for Mac-1 and Gr-1, then analyzed with flow cytometry, as described in the Experimental procedures. The data shows one of at least four experiments performed with similar results, each evaluating two mice per group. 
interest since it should provide a new kind of immunotherapy. Considering the pleiotropic actions of isoflavones, they may rather be reconsidered more generally as "nutraceuticals". This term was coined from the words "nutrition" and "pharmaceuticals", defining any food substance which provides health benefits, including the prevention and treatment of disease. ${ }^{19,20)}$ The presumable strength of isoflavones and $\beta$-glucan could rely on the unique combination of several features with different potencies in natural molecules that provide health benefits.

Acknowledgements We thank Hiromi Kawaminami for her excellent technical assistance.

\section{REFERENCES}

1) Setchell K. D., Cassidy A., J. Nutr., 129, 758S-767S (1999).

2) Fotsis T., Pepper M., Adlercreutz H., Hase T., Montesano R., Schweigerer L., J. Nutr., 125, 790S-797S (1995).

3) Casagrande F., Darbon J. M., Biochem. Pharmacol., 61, 1205-1215 (2001).

4) Arora A., Nair M. G., Strasburg G. M., Arch. Biochem. Biophys., 356, 133-141 (1998)

5) Keung W. M., Vallee B. L., Proc. Natl. Acad. Sci. U.S.A., 90, 12471251 (1993).

6) Messina M. J., Persky V., Setchell K. D., Barnes S., Nutr. Cancer, 21,
113-131 (1994).

7) Adlercreutz H., Lancet Oncol., 3, 364-373 (2002).

8) Yadomae T., Yakugaku Zasshi, 120, 413-431 (2000).

9) Yadomae T., Ohno N., Recent Res. Devel. in Chem. \& Pharm. Sciences, 1, 23-33 (1996).

10) Ohno N., Miura N. N., Nakajima M., Yadomae T., Biol. Pharm. Bull., 23, 866-872 (2000).

11) Ohno N., Nameda S., Harada T., Miura N. N., Adachi Y., Nakajima M., Yoshida K., Yosida H., Yadomae T., Inter. J. Med. Mushr., 5, 359368 (2003).

12) Harada T., Miura N. N., Adachi Y., Nakajima M., Yadomae T., Ohno N., Biol. Pharm. Bull., 25, 931-939 (2002).

13) Ohno N., Harada T., Masuzawa S., Miura N. N., Adachi Y., Nakajima M., Yadomae T., Inter. J. Med. Mushr., 4, 13-26 (2002).

14) Nameda S., Harada T., Miura N. N., Adachi Y., Yadomae T., Nakajima M., Ohno N., Immunopharmacol. Immunotoxicol., 25, 321-335 (2003).

15) Harada T., Miura N. N., Adachi Y., Nakajima M., Yadomae T., Ohno N., J. Interferon Cytokine Res., 22, 1227-1239 (2002).

16) Harada T., Miura N. N., Adachi Y., Nakajima M., Yadomae T., Ohno N., J. Interferon Cytokine Res., 24, 478 - 489 (2004).

17) Harada T., Miura N. N., Adachi Y., Nakajima M., Yadomae T., Ohno N., Biol. Pharm. Bull., 26, 1225-1228 (2003).

18) Yamakoshi J., Piskula M. K., Izumi T., Tobe K., Saito M., Kataoka S., Obata A., Kikuchi M., J. Nutr., 130, 1887-1893 (2000).

19) Kalra E. K., AAPS Pharm. Sci., 5, E25 (2003).

20) Uehar M., Arai Y., Watanabe S., Adlercreutz H., Biofactors, 12, $217-$ 225 (2000). 